\title{
Malcolm A. Holliday, M.D, January 12, 1924-March 26, 2014
}

\author{
Steven J. Wassner • Russell W. Chesney • \\ Aaron Friedman • Cyril Chantler • Anthony A. Portale
}

Received: 8 April 2014 /Revised: 8 April 2014 / Accepted: 15 April 2014 / Published online: 11 May 2014

(C) IPNA 2014

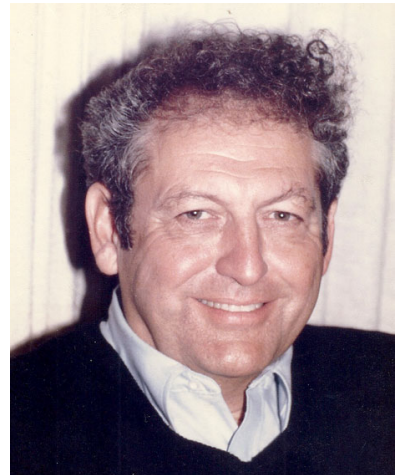

Malcolm A. Holliday, M.D., died on March 26, 2014 at the age of 90 . Widely known as Mac, he was a major figure in pediatric nephrology, and one of the great pediatric physiologists of the second half of the 20th century.

\section{S. J. Wassner $(\square)$}

Division of Pediatric Nephrology \& Hypertension, Penn State Hershey Children's Hospital, Penn State University College of Medicine, Hershey, PA, USA

e-mail: swassner@psu.edu

R. W. Chesney

University of Tennessee Health Science Center,

Department of Pediatrics, Memphis, TN, USA

\section{A. Friedman}

University of Minnesota,

420 Delaware Street SE, Minneapolis, MN, USA

C. Chantler

UCL Partners, Academic Health Science Partnership,

LondonW1T 7HA, UK

\section{A. A. Portale}

UCSF Medical Center, San Francisco, CA, USA
Born in Staunton, Virginia, Mac excelled as a student, entering college at age 16 and the University of Virginia Medical School at 19. He graduated Alpha Omega Alpha just 3 years later, owing to the acceleration of medical education during the war years. Mac was an intern at Boston Children's and later joined Dr. Gamble's lab at Harvard University. There, working with Dr. William Wallace, he helped build one of the earliest flame photometers. The ability to readily measure sodium and potassium led to a number of early studies on electrolyte composition. He continued his research studies in the laboratory of Dr. Daniel Darrow at Yale University. Early research papers demonstrated an understanding of the importance of integrating body systems, a theme that characterized his entire career.

In his initial academic position at the University of Indiana, Mac's interest in renal physiology coalesced with the clinical electrolyte problems of children with inherited tubular disorders and congenital renal defects. Almost 60 years ago, in 1957, Mac and Dr. William Segar published their seminal paper, "The maintenance need for water in parenteral fluid therapy." Their formula for maintenance energy and fluid requirements, the famous 100/50/20 rule, is still the standard when ordering intravenous fluids for pediatric patients.

In 1963 Mac accepted the position of Physician-in-Chief of Oakland Children's Hospital, and 3 years later moved across the San Francisco Bay to become Professor of Pediatrics and Chief of the Division of Pediatric Nephrology at University of California San Francisco, a position he held for over two and a half decades. This was the beginning of the age of dialysis and transplantation and, given Mac's background in metabolism and body composition, it is understandable that he turned his attention to the major problem of growth in children with chronic kidney disease (CKD). Utilizing both animal experiments and clinical studies, he demonstrated that CKD was associated with diminished growth and metabolic defects at the muscle level. He showed that protein turnover rates were 
altered in CKD and that dietary supplementation led to improved growth rates.

Mac not only performed and published these studies, he influenced the way data were analyzed and reported. Through his many publications and talks he championed the use of standard deviation scores for growth assessment, a practice that is now the norm. Mac, along with Martin Barrett and Robert Vernier, took over the editorship of the textbook Pediatric Nephrology, which he edited for two editions. Now in its sixth edition, it still maintains the emphasis on whole body integrative physiology that was his hallmark contribution to the field.

Mac espoused the importance of collaboration. Many of his early studies were done in conjunction with individuals who became leaders in pediatric and internal medicine. He was a tireless advocate of collaborative studies, and in 1977 he organized the first and later the third International Conference on Growth and Nutrition in Children with Chronic Renal Disease.

Mac was quietly persistent in his work and more interested in getting it right than in taking credit. He was always willing to re-examine his own work in the light of new evidence. He was extraordinarily generous with his time and a wonderful teacher. Under his leadership, his division became a center for the training of both fellows and visiting physicians. His scientific career spanned over 60 years of active work, and while he formally retired from the University of California at San Francisco at age 67, he published his last nephrology paper at age 83 .

No discussion of Mac would be complete without mentioning his dear wife Millie. Wherever they were, it was Millie who made their house a home, raised their five lovely children and graciously welcomed all. After retirement, Mac and Millie spent a decade in a home they built in the Point Reyes area of Northern California. They hiked the seashore, became involved in the community and welcomed friends who were always anxious to visit and view the magnificent scenery. Their love for each other was visible to all.

For over seven decades Malcolm Holliday explored and explained how our bodies adapted to stress, including that of chronic kidney disease. His work has been at the foundation of the care we provide to pediatric patients. Mac Holliday was a bold, innovative thinker, a rigorous researcher and a tireless worker for the improvement of health care. Such individuals are rare, and we are all saddened by his departure. 